\title{
A Case Report of Family with Congenital Non- Syndromic Hearing Loss (NSHL) with Variants of Uncertain Significance (VUS) in GATA3 and COLA43 Genes
}

\author{
Ashok Reddy Banala, Shehnaz Sultana, Sai Priya Reddygari, Pratibha Nallari, Sujatha Madireddy and \\ Venkateshwari Ananthapur*
}

Institute of Genetics and Hospital for Genetic Diseases, Osmania University, India

Submission: December 12, 2020; Published: January 05, 2021

"Corresponding author: Venkateshwari Ananthapur, Institute of Genetics and Hospital for Genetic Diseases, Osmania University, India

\begin{abstract}
Objectives: Hearing impairment is the frequent sensory deficit in human populations. Non-syndromic hearing loss accounts for $70 \%$, with autosomal recessive, autosomal dominant, $X$ linked and mitochondrial mode of inheritance. The case report represents a family with two siblings having congenital non-syndromic hearing loss (NSHL), and mother with acquired deafness. The objective of the case report was to identify the gene mutations resulting in NSHL in the family.

Methods: Next generation sequencing (NGS) based deafness gene panel was used to identify the gene variants in the family.

Results: Next generation sequencing (NGS) based deafness gene panel results identified variant of uncertain significance (VUS) c.709_710insG (p. Ser237ArgfsTer67) in exon 3 of GATA3 (+) (ENST00000379328.3) gene in heterozygous condition with autosomal dominant pattern in the 7 years old male proband and his mother. Whereas a heterozygous missense variant c.872G>T (p. Gly291Val) with uncertain significance (VUS) in exon 15 of COL4A3 (+) (ENST00000396578.3) gene was identified only in the mother.
\end{abstract}

Conclusion: Evaluating the causes of non-syndromic hearing loss is important for diagnosis, clinical management, genetic counselling, and potential prevention.

Keyword: Non-syndromic hearing loss; Congenital; GATA3; COLA43

Abbreviations: NSHL: Non-Syndromic Hearing Loss; NGS: Next Generation Sequencing; VUS Variant of Uncertain Significance

\section{Introduction}

Hearing impairment is the frequent sensory deficit in human populations. Hearing loss occurs in 291 out of every 100,000 births in India [1]. Hearing loss has different etiologies and approximately $1 \%$ of all human genes are involved in the hearing process [2]. The two types of hearing loss caused by genetics are syndromic and non-syndromic. $30 \%$ of the hearing loss cases are syndromic, which presents abnormalities along with hearing impairment, whereas $70 \%$ of the cases are non-syndromic, where there are no other problems associated with hearing loss. Nonsyndromic hearing loss is inherited in the following modes: autosomal recessive $(80-85 \%)$, autosomal dominant (10-15\%), $\mathrm{X}$ linked $(1 \%)$ and mitochondrial $(<1 \%)$. Non-syndromic hearing loss is caused due to variants in more than 150 genes [3-5]. Hearing loss can have a large impact on communication, levels of education, and psychosocial development and it is responsible for a subsequent decline in quality of life, especially in children. Evaluating the causes of hearing loss is important for clinical management, genetic counselling, and potential prevention.

\section{Case Presentation}

The case report presents a family of 7 years old male and 5 years old female siblings born to non-consanguineous parents with total congenital deafness and their mother with partial acquired deafness. The institutional ethical committee has approved the present study. Prior informed consent was obtained from the patient's family. Both the siblings along with their mother has been evaluated for pathogenic variations by next generation sequencing (NGS) based deafness gene panel. The 
test results identified variant of uncertain significance (VUS) c.709_710insG (p. Ser237ArgfsTer67) in exon 3 of GATA3 (+) (ENST00000379328.3) gene in heterozygous condition with autosomal dominant pattern in the 7 years old male proband. The same GATA3 variant c.709_710insG (p. Ser237ArgfsTer67) in exon 3 was also detected in heterozygous state in his affected mother along with a heterozygous missense variant c.872G>T (p. Gly291Val) with uncertain significance (VUS) in exon 15 of COL4A3 (+) (ENST00000396578.3) gene. The heterozygous COL4A3 variant (p. Gly291Val) that was detected in the affected mother was not detected in both the siblings. Interestingly the test report of 5 years old female sibling does not indicate any pathogenic variations including the variations which was detected in the mother and other sibling.

\section{Discussion}

GJB2 is the most prominent deafness gene. However, in the present family variants of unknown significance (VUS) were identified in the GATA3 and COL4A3 genes. GATA binding protein 3 (GATA3) gene is located on chromosome 10p15, belongs to the family of zinc finger transcription factor and binds to the $[\mathrm{A} / \mathrm{T}]$ GATA $[\mathrm{A} / \mathrm{G}]$ consensus sequence. GATA3 gene consists of two N-terminal transactivating domains (TA1 and TA2) and two C-terminal zinc finger domains ( $\mathrm{ZnF} 1$ and $\mathrm{ZnF} 2)$. GATA3 gene is a key regulator of auditory system development as it orchestrates cell differentiation [6,7] and expressed in most embryonic tissues [8] and almost in all auditory cell types [6]. A heterozygous single base pair insertion in exon 3 of the GATA3 gene (chr10: g.8100735_8100736insG; Depth: 27x) identified in the 7 years old proband results in a frameshift and premature truncation of the protein 67 amino acids downstream to codon 237 (p. Ser237ArgfsTer67; ENST00000379328.3). The variant has not been reported in the 1000 genomes, ExAC. The in-silico prediction\# of the variant is found to be damaging by MutationTaster2. The reference region is conserved across species. Although the variant c.709_710insG (p. Ser237ArgfsTer67) identified in the proband in exon 3 of GATA3 gene is of uncertain significance (VUS), mutations in GATA3 gene causes hypoparathyroidism, sensorineural deafness, and renal dysplasia, also known as Barakat syndrome (OMIM\#146255) [9]. It is also possible that mild mutations in GATA3 could cause non-syndromic hearing loss. The variants observed in the proband and mother indicates the deregulated functioning GATA3 gene and result in non-syndromic hearing loss.

COL4A3 gene is located on chromosome $2 q 36-37$ and encodes an $\alpha 3$ collagen chain of type IV collagen [10,11]. Zehnder et al. [12] discovered that the $\alpha 3$ chain is specifically expressed in collagen bundles in the basement membrane, spiral ligament, and spiral margin in human cochlea, suggesting that hearing loss may be due to cochlear micromechanical changes and are consistent with the helical ligament dysfunction [12]. A heterozygous missense variation in exon 15 of the COL4A3 gene (chr2: g.228119415G>T;
Depth: 59x) may results in the amino acid substitution of Valine for Glycine at codon 291 (p. Gly291Val; ENST00000396578.3) which was detected in probands mother. Earlier study also reported similar variant in heterozygous state, in a patient affected with late-onset end stage renal disease (ESRD) [13]. The p. Gly291Val variant has not been reported in the 1000 genomes, ExAC. The in-silico predictions\# of the variant are probably damaging by PolyPhen-2 (HumDiv), SIFT, LRT and Mutation Taster [2]. The reference codon is conserved across species. Mutations in COL4A3 gene also cause Alport syndrome-2 (OMIM\#203780) and Alport syndrome-3 (OMIM\#104200), a hereditary disorder of the basement membrane, resulting in a glomerulonephropathy causing renal failure. Progressive deafness and ocular anomalies may also occur [9].

\section{Conclusion}

In conclusion, genetic diagnosis plays an important role in the treatment and management of both congenital and later onset hearing loss. Success of cochlear implant may also depend on the genetic cause of the hearing loss [14]. It is utmost important to understand the relative contribution of genes involved in non-syndromic hearing loss (NSHL) in order to apply molecular diagnostics in clinical practice. Genetic testing also helps in offering pre- and post-natal diagnosis in the families with the history of non-syndromic hearing loss.

\section{References}

1. Ministry of Statistics and Programme Implementation, Government of India.

2. Friedman TB, Griffith AJ (2003) Human nonsyndromic sensorineural deafness. Annu Rev Genomics Hum Genet 4: 341-402.

3. Van Camp G, Smith RJH. Hereditary Hearing Loss Homepage.

4. (2020) Deafness Variation Database.

5. Azaiez H, Booth KT, Ephraim SS, Crone B, Ziegelbein EAB, et al. (2018) Genomic landscape and mutational signatures of deafness-associated genes. Am J Hum Genet 103(4): 484-497.

6. Milo M, Cacciabue Rivolta D, Kneebone A, Van Doorninck H, Johnson C, et al. (2009) Genomic analysis of the function of the transcription factor gata3 during development of the mammalian inner ear. PLoS One 4: e7144.

7. Appler JM, Goodrich LV (2013) Connecting the ear to the brain: Molecular mechanisms of auditory circuit assembly. Prog Neurobiol 93(4): 488-508.

8. Boualia SK, Gaitan Y, Tremblay M, Sharma R, Cardin J, et al. (2013) A core transcriptional network composed of Pax $2 / 8$, Gata3 and Lim1 regulates key players of pro/mesonephros morphogenesis. Dev Biol 382(2): 555-566.

9. McKusick VA (1998) Mendelian Inheritance in Man. A Catalog of Human Genes and Genetic Disorders. Baltimore: Johns Hopkins University Press (12 ${ }^{\text {th }}$ edition).

10. Jingyuan $X$, Xiaoxi W, Hong R, Weiming Wang, Zhaohui Wang, et al. (2014) COL4A3 mutations cause focal segmental glomerulosclerosis. J Mol Cell Biol 6: 498-505. 
11. Storey H, Savige J, Sivakumar V, Abbs S, Flinter FA (2013) COL4A3/ COL4A4 mutations and features in individuals with autosomal recessive Alport syndrome. Journal of the American Society of Nephrology 24(12): 1945-1954.

12. Zehnder AF, Adams JC, Santi PA (2005) Distribution of type IV collagen in the cochlea in Alport syndrome. Archives of Otolaryngology- Head \& Neck Surgery 131(11): 1007-1013.
13. Julia H, Sperandio BL, Ruessmann D, Pagel JG, Alberer M, et al. (2010) Novel heterozygous COL4A3 mutation in a family with late-onset ESRD. Pediatric Nephrology 25(8): 1539-1542.

14. Miyagawa M, Nishio SY, Usami S (2016) A comprehensive study on the etiology of patients receiving cochlear implantation with special emphasis on genetic epidemiology. Otol Neurotol 37(2): e126-e134.

Your next submission with Juniper Publishers
will reach you the below assets
- Quality Editorial service
- Swift Peer Review
- Reprints availability
- E-prints Service
- Manuscript Podcast for convenient understanding
- Global attainment for your research
- Manuscript accessibility in different formats
( Pdf, E-pub, Full Text, Audio)
- Unceasing customer service
Track the below URL for one-step submission
https://juniperpublishers.com/online-submission.php

